\title{
Trying Not to Try: The Paradox of Intentionality in Jazz Improvisation and its Implications for Organizational Scholarship
}

Colin M. Fisher, UCL School of Management, U.K. colin.fisher@ucl.ac.uk

Ozumcan Demir-Caliskan, UCL School of Management, U.K. o.caliskan.17@ucl.ac.uk

Mel Yingying Hua, UCL School of Management, U.K. mel.hua.16@ucl.ac.uk

Matthew A. Cronin, George Mason University, U.S.A. mcronin@gmu.edu

Colin M. Fisher is an associate professor of organizations and innovation at UCL School of Management. He studies temporal dynamics in team leadership, helping, creativity, and improvisation. Colin received his Ph.D. in organizational behavior from Harvard University while moonlighting as a jazz trumpet player, most notably with Grammy-nominated Either/Orchestra.

Ozumcan Demir-Caliskan is a PhD student at UCL School of Management. Her research focuses on how new technologies and new forms of organizing affect creative processes and the experience of creative workers. She received her Master of Science and Bachelor's degrees in Industrial Design at Middle East Technical University (METU).

Mel Yingying Hua is a PhD student at UCL School of Management. Her research uses qualitative and quantitative methods to investigate how individuals and teams develop, evaluate, and execute their ideas. Mel received her Bachelor's from National University of Singapore and worked as a journalist and marketer in various start-ups.

Matthew A. Cronin is an associate professor of management at George Mason University. He received his $\mathrm{PhD}$ in organizational behavior from Carnegie Mellon University. Cronin's research seeks to understand how collaboration can help produce creative ideas, and what it takes to then bring these ideas to fruition.

To appear in:

Fisher, C. M., Demir-Caliskan, O., Hua, M. Y., \& Cronin, M. A. (in press). Trying not to try: The paradox of intentionality in jazz improvisation and its implications for organizational scholarship. In R. Bednarek, M. P. Cunha, J. Schad, \& W. Smith (Eds.) Interdisciplinary Dialogues on Organizational Paradox, Research in the Sociology of Organizations, Vol. 73B (pp. 125-139). Melbourne: Emerald Publishing. 


\begin{abstract}
Organizational scholars have long been interested in how jazz musicians manage tensions between structure and freedom, plans and action, and familiarity and novelty. Although improvisation has been conceptualized as a way of managing such paradoxes, the process of improvisation itself contains paradoxes. In this essay, we return to jazz improvisation to identify a new paradox of interest to organizational scholars: the paradox of intentionality. To improvise creatively, jazz musicians report that they must "try not to try", or risk undermining the very spontaneity that is prized in jazz. Jazz improvisers must therefore control their ability to relinquish deliberate control of their actions. To accomplish this, they engage in three interdependent practices. Jazz musicians intentionally surrender their sense of active control ("letting go") while creating a passive externalized role for this sense of active control (using a "third ear"). Letting go allows new and unexpected ideas to emerge, while the metaphorical third ear can identify promising ideas or problematic execution and, in doing so, re-engage active agency ("grabbing hold"). Examining the practices within creative improvisation reveals the complexity of the lived experience of the paradox, which we argue suggests further integration among organizational research on improvisation, creativity, and paradox.
\end{abstract}

\title{
Keywords:
}

1. jazz

2. music

3. improvisation

4. intention

5. creativity

6. paradox 
[This introductory section is from the experience of the first author, who worked as a professional jazz trumpet player for twelve years before embarking on his second career as an organizational researcher]

I always found jazz improvisation somewhat mysterious, even when it was my job. How could a group of people come together to spontaneously play something that none of us had ever thought of before or could ever play again? I have struggled with this question as both a musician and an organizational researcher. And, to me, one of the most interesting parts of the mystery of jazz improvisation is that you need to try to make spontaneous creativity occur, but that trying seems to kill the very thing you seek.

Like many young jazz musicians, I dedicated myself wholly to practicing. The summer after my freshman year in college, I practiced 4-8 hours per day and performed on the street with my bandmates when weather permitted (besides the "regular" gigs at nights and on weekends). I tried to maximize my learning from practice - I analyzed every practice session using a self-designed reflection sheet, giving myself something to work on for the next day. However, I quickly noticed that the mindset I adopted during those hours of practice seemed useless when I was performing. Noticing little imperfections or trying to implement a principle I was working on in the practice room made improvising feel contrived. Moreover, what seemed to be healthy experimentation and reflection during practice felt counter-productive during performance.

My tendency to intentionally use what I practiced in my live improvisations was noted by my teachers (notably John McNeil and Fred Hersch, quoted below), who tried to help me break this habit. I recall Bob Brookmeyer (famed trombonist/composer who was coaching one of my ensembles) telling me to "stop listening like your ears are on your head" and, instead to "listen like one of your ears is on the piano." This admonition to listen as if I were outside of myself (and thus, not in direct control) was similar to the advice in self-help 
books for jazz musicians on this topic, such as Nachmanovitch's (1990) Free Play or Werner's (1996) Effortless Mastery. Clearly, I was not alone in trying to work out how to blend the effortful work of learning my craft with the supposedly "effortless" experience that master improvisers reported.

Yet, even then, the idea that we simply let go and "discover the master within" (Werner, 1996) didn't ring totally true to me. The knowledge of the structure and language of jazz and the technical skills to play one's instrument are built intentionally through conscious control. Those knowledge and skills are also deployed intentionally - when we perform, we clearly are trying to improvise and trying to be creative. Moreover, there have been many times when I've needed to exert conscious control while improvising - as a little nudge to get out of a familiar pattern, when I felt out of synch with my bandmates, when someone made a mistake, or simply when I needed to remember a difficult passage in a melody. And, I've worked with enough accomplished musicians to know that I'm not the only one experiencing this. The trick is to be able to control ones' own conscious control - to loosen it and tighten it when needed.

This apparent tension gets to the heart of the paradox we explore here: How do jazz musicians control their own operation of control? How can they "try not to try"? The purpose of this essay is to use jazz improvisers' paradoxical experience with intentional control to conceptualize the paradox of intention, how to manage it, and discuss its implications for managing tensions in organizations.

\section{Paradoxes in Organizations and Jazz Improvisation}

In organization theory, paradoxes are described as having "contradictory yet interrelated elements - elements that seem logical in isolation but absurd and irrational when appearing simultaneously" (Lewis, 2000, p. 760). For instance, organizations must simultaneously provide the freedom to explore new ideas and impose structure and order that 
maximize efficiency (Adler, Goldoftas, \& Levine, 1999). Scholars have suggested a variety of responses to such paradoxes, such as adopting paradoxical mindsets (e.g., Miron-Spektor, Ingram, Keller, Smith, \& Lewis, 2018; Ingram, Lewis, Barton, \& Gartner, 2016; Waldman, Putnam, Miron-Spektor, \& Siegel, 2019) or separating contradictory elements in time or space (e.g., Poole \& Van de Ven, 1989; Chung \& Beamish, 2010).

In organizations, improvisation can also be a way of managing a key tension in organizations: the tension between planning and action (Clegg, Cunha, \& Cunha, 2002). Organizations require formal, strategic plans that enable coordination, but also need to respond to situational demands in novel and unforeseen ways (Orlikowski, 1996; Fisher \& Amabile, 2009). Instead of planning and action as two opposing, irreconcilable poles, improvisation relates the two, in that it is grounded in pre-existing plans, yet adapts them as circumstances demand. In other words, "improvisation brings planning and action together but replaces neither" (Clegg et al, 2002, p. 489). Thus, improvisation itself can be a process for managing important tensions in organizations (for reviews of research on organizational improvisation, see Hadida, Tarvainen, \& Rose, 2015; Cunha, Miner, \& Antonacopoulou, 2017; Fisher \& Barrett, 2019).

But, the practice of improvisation also introduces tensions that actors need to navigate. To understand these tensions, we offer a brief synopsis of how jazz improvisation works. Jazz musicians spend thousands of hours throughout their career practicing musical patterns, such as scales and licks, so that they are nearly as automatic as words in a language one is fluent in. They, in short, become experts in the raw materials of music - chords, scales, and rhythms. They also learn features of a common set of "standard" songs: melody, harmony, and rhythm. Generally, the melody both begins and ends a performance of a song and affords little improvisation at these times, so it is played similarly by all jazz musicians. After the first playing of the melody, the rhythm section (i.e., piano/guitar, bass, drums) 
repeats the harmony and rhythm that undergirds that melody. This harmonic and rhythmic structure provides a flexible basis for soloists to improvise new melodies. To accompany the soloist, the rhythm section may make certain harmonic and rhythmic adjustments. Soloists take turns improvising on this structure and then play the melody again to end the song. (see Berliner, 1994 for an in-depth analysis of jazz culture and performance).

In the 1990s, many scholars became interested in jazz because they noted that organizational theory was suited to explaining planned, controlled behavior, but struggled to explain the emergence and dynamism in contemporary organizations. Notably, in a special issue of Organization Science focused on improvisation, Weick (1998, p. 551) argued that, to better understand organizing, scholars should use jazz improvisation as a generative metaphor:

To watch jazz improvisation unfold is to have palpable contact with the human condition ... If theorists take improvisation seriously, they may be able to give form to the idea of "becoming realism" (Chia,1996) and add to what we already know. They may, for example, be able to do more with the simultaneous presence of seeming opposites in organizations than simply label them as paradoxes. There is currently an abundance of conceptual dichotomies that tempt analysts to choose between things like control and innovation, exploitation and exploration, routine and non-routine, and automatic and controlled, when the issue in most organizations is one of proportion and simultaneity rather than choice. Improvisation is a mixture of the pre-composed and the spontaneous, just as organizational action mixes together some proportion of control with innovation, exploitation with exploration, routine with nonroutine, automatic with controlled.

As Weick points out, jazz improvisation contains many paradoxes of interest to organizational scholars, including tensions between structure and freedom, formal plans and emergent action, and familiarity and novelty. The way jazz musicians manage the tension between structure and freedom has been of particular interest to organizational scholars: constraining structures (i.e., rules and routines about what and how to play) simultaneously enable spontaneous creativity and reliable performance. In a review of the literature, Hadida, Tarvainen and Rose (2015) summarized organizational scholars' interest in jazz improvisation thusly: "Jazz improvisation provides a wealth of parallels to [organizational 
improvisation]. It starts from a certain structure that frames improvisation but does not cage it” (p. 444). In other words, action in both jazz and organizations is informed by structures like strategic plans and formal operating procedures. Yet, action is also spontaneous, introducing new and unforeseen elements. The particular structures of jazz were promising because they not only prevented spontaneous action from devolving into chaos, but also seemed to enable collaborative, creative music with their flexibility.

While it has become clear that the jazz approach to improvisation has been generative for organization research, the rich and lived experiences of jazz improvisation has yet to be fully explored. Indeed, recent reviews of the organizational improvisation have also argued that the subjective experience of the process of improvising is notably absent from organizational theorizing (Cunha et al., 2017; Hadida et al., 2015). Specifically, Fisher and Barrett (2019) argued that the experience of improvising is itself paradoxical. For instance, that the danger of failure is what creates excitement in artistic improvisation, but organizational values of control and planning dampen these potential positive experiences. Thus, in the following sections, we explore another such paradox in the micro-processes of improvisation itself - the tension between intentional control and letting go. Examination of this tension highlights an overlooked paradox in jazz improvisation that is essential to the lived experience of jazz musicians, who represent an informative and extreme case of dealing with tensions and paradox. In doing so, we answer calls to take a practice perspective on organizational paradoxes (Le \& Bednarek, 2017) and draw lessons for organizational scholarship.

\section{Intentionality and Jazz Improvisation}

"When I'm playing at my best, I find that I'm not thinking about anything. I can actually have the sensation of going outside of myself and observing myself while I'm performing. It's very strange. You can actually listen while you're playing, and listen to the rest of the group, and be completely objective and relaxed. At the same time, you are reacting to everything around you. ... You carry along all the scales and all the chords you learned, and then you take an intuitive leap into the music. Once you 
take that leap you forget all about those tools. You just sit back and let divine intuition take over." (Peplowski, 1998, p. 561)

In this quotation, saxophonist Ken Peplowski summarizes well the paradox of intentionality he experienced when improvising creatively: He felt that he was not "thinking about anything" and was "going outside" of himself to "actually listen while [he's] playing". Like Peplowski, jazz musicians often report that they do not experience improvising as something that they are intentionally controlling, but as something that emerges through them (Nachmanovitch, 1990; Eisenberg, 1990). Although they have typically spent years learning musical material and can therefore choose when and what to play, jazz musicians view intentionally thinking about what to play as something dangerous and antithetical to improvisation.

Among jazz musicians, spontaneity and creativity are crucial values. Spontaneity and surprise, by definition, cannot be fully pre-planned - there must be uncertainty about what is to come. Because improvisation is also a creative process (Fisher \& Amabile, 2009; Fisher, Ananth, \& Demir-Caliskan, 2020), there will be some degree of novelty - something new that is different from what has come before and is therefore unknown. It is well documented that, although jazz musicians are clearly improvising on purpose, they cannot be planning and intentionally rendering each note or phrase. Trumpeter Doc Cheatham articulated this idea, saying: "I have no idea what I am going to do when I take a solo... That's the thing that I don't understand myself and I've been asked about it so many times. When I play a solo, I never know any more about what I am going to play than you do" (Berliner, 1994, p. 2). On some level, then, being spontaneous means giving up control.

Since spontaneity cannot be pre-planned, trying to be spontaneous and creative is seen as self-defeating. As violinist and author Stephen Nachmanovitch put it, "Although I now know that I must give up the need to control, I cannot intentionally decide to give it up, or simulate giving it up, in order to make the music rejuvenate itself out of a stuck place. That 
just doesn't work. The surrender has got to be genuine, uncontrived" (Nachmanovitch, 1990, p. 141). This phenomenon is so pervasive in jazz that nearly all interviews with musicians contain at least a trace of it. Self-help books for jazz musicians frequently discuss how to (intentionally) relinquish agency when improvising - to get out of your own way (e.g., Nachmanovitch, 1990; Werner, 1996). This serendipitous element, which critic Whitney Balliett famously called "the sound of surprise," is core to jazz (Balliett, 1959). But how can you intentionally and genuinely surprise yourself?

There are two contradictory ways in which intention plays a role in jazz improvisation. On the one hand, jazz musicians know they must "try not to try" in order to be spontaneous - they must intentionally relinquish conscious control of their actions and allow intuition to almost effortlessly guide their actions. On the other hand, they must develop control over their ability to relinquish control. Moreover, they simultaneously maintain a sense of being a separate "listener," who oversees and, when necessary, can intervene to reassert agency. In the following sections, we examine this experience of intentionally relinquishing agency in jazz improvisation, detailing the attributes of this paradox (including how intention is both included and excluded from improvising) and how jazz musicians have reported dealing with this paradox. Importantly, we highlight that the tension between enacting and relinquishing intentional control is asymmetrical - it is more difficult to let go of control than to re-engage it.

Intentional Aspects of Jazz Improvisation. Intention is involved in two main facets of jazz improvisation: (a) acquiring and practicing musical material until deploying it feels easy and (b) intending to relinquish agentic control. First, jazz musicians prepare themselves to improvise by seeking out and absorbing material that may be useful in their performances. As Berliner (1994) detailed, decisions about what material to practice and study strongly influence musicians' improvisational style and vocabulary: 
Performers constantly make selective judgments about materials for study... They work on some pieces and not others, absorb some new phrases and not others, experiment with their use in some roles and not others, explore the cross-relationships among some theoretical materials and not others. Each decision, even on the most simple matter, has a direct impact on the performer's developing style of improvisation, further delineating the player's personal voice. It is in this sense that [pianist] Walter Bishop Jr. regards improvisation as "the product of all that players have experienced, all the music they've studied, absorbed, deleted and refined. . . This music is an evolutionary thing. You study and apply. Study and apply.” (Berliner, 1994, p. 494)

This learning of craft is an essential antecedent to jazz improvisation. Musicians listen to recorded improvisations (often laboriously committing them to memory) and practice particular harmonic, melodic, and rhythmic patterns. Although the goal is not to reproduce this learned material on stage, such practice creates a vocabulary of material that musicians can draw from, transform, and abstract. Though preparing to improvise is effortful, the use of intention here is similar to any work situation that requires developing skills and expertise.

Second, jazz musicians are open (and often actively trying) to relinquish intentional control. This use of intention is less common. Pianist Barry Harris characterizes the soloist's optimum state as "calm but alert, ready to go with any possibility." (Berliner, 1994, p. 219). For a jazz musician, entering into a state of readiness is something that one intends to happen, like actively getting into the ocean in order to then be carried away by a wave. Thus, one needs to be willing and able to be in a state where the conscious mind is quiet enough and out of the way, to go with the tide of the music. The contrast between the two states echoes the distinction made by cognitive psychologist between an effortful, conscious mode of processing and an effortless, automatic mode (Smith \& DeCoster, 2000). Jazz musicians clearly intend to enter a state of non-intentional action because "surrender of control is essential to the jamming experience" (Eisenberg, 1990), and, because efforts to mimic or simulate non-intentionality are counterproductive, musicians must learn to have some degree of control over this boundary. This is the moment of intersection between intentional and non-intentional action. 
Unintentional Aspects of Jazz Improvisation. While it may seem simple to intentionally relinquish control, it is easier said than done. Expert jazz musicians often feel that they are not agents who control where the music goes. As singer Camen Lundy described (Berliner, 1994, p. 392): “Sometimes, I really feel that I am just the vehicle, the body, and that something is really singing through me, like I am not controlling everything that I am singing." Similarly, violinist Stephane Grappelli noted that he felt like he was "half-sleeping" when he was improvising well (Nachmanovitch, 1990, p. 207). In other words, jazz musicians commonly feel as if intention interferes with this state because trying to get carried away or trying to be in an automatic mode is largely futile. As such, achieving the experience of letting go described above is quite difficult, and many musicians struggle to achieve it consistently (Eisenberg, 1990; Fisher \& Barrett, 2019).

The unintentional facets of improvisation are evident in (a) relying on intuition to automatically deploy musical materials, b) generating material that is truly novel (to the improviser) and (c) listening and responding reflexively in the moment. Jazz musicians allow their unconscious to direct how their craft is deployed. Even though they spend years learning scales, patterns, and the improvised solos of their heroes, jazz musicians avoid intentionally using these materials during their improvisations for fear of killing the spontaneity that jazz is meant to evoke. As trumpeter John McNeil put it: "If you try to force something that you've learned into your solos ... it will sound really contrived, like it doesn't have anything to do with what you just played before it” (Berliner, 1994, p. 263). They trust that they will improvise in response to feelings and impulses that emerge in the moment. "Improvisation is an intuitive process for me now," [multi-instrumentalist] Arthur Rhames asserts, "but in the way in which it's intuitive," he adds, "I'm calling upon all the resources of all the years of my playing at once: my academic understanding of the music, my historical understanding of the music, and my technical understanding of the instrument that I'm playing. All these 
things are going into one concentrated effort to produce something that is indicative of what I'm feeling at the time I'm performing." (Berliner, 1994, p. 16). The link between their musical knowledge and the ability to render it through their instruments is like speaking a language they have learned. Just as people who speak a language fluently do not worry about whether they will be able to respond in everyday conversations, jazz improvisers know they can play something coherent in almost any musical situation.

By letting go of trying to play specific things they already know, jazz musicians can play music they had not yet imagined or thought were possible. Playing creatively because one is not trying to play creatively is analogous to dreaming: Very few of us have dreams that we would see ourselves thinking up with our waking minds, in which we combine our experience and knowledge in previously unimagined ways. While jazz improvisation does not necessarily deviate from normal as far as dreams do, it evokes combinations and alterations that would be difficult to generate consciously. This leads musicians like pianist Fred Hersch to play things that they did not feel capable of creating through other means: "I played all this technical stuff that I couldn't sit down and play now-even if I practice it for eight hours. At that moment, the music was happening. Everything just fell into place in my hands and in my head" (Berliner, 1994, p. 217).

Letting go of intention also allows jazz improvisers to focus on responding to what they and others have already played (Fisher \& Amabile, 2009). As saxophonist Lee Konitz put it, "If you're not affected and influenced by your own notes when you improvise, then you're missing the whole essential point" (Berliner, 1994, p. 193). Drummer Max Roach similarly describes how he responded reflexively to his own playing:

After you initiate the solo, one phrase determines what the next is going to be. From the first note that you hear, you are responding to what you've just played: you just said this on your instrument, and now that's a constant. What follows from that? And then the next phrase is a constant. What follows from that? And so on and so forth.... When I play, it's like having a conversation with myself. (Berliner, 1994, p. 192) 
Because each musical phrase is unintended and may be new and surprising for the person playing it, it invites new directions for what to play next. This reflexiveness (i.e., responding to yourself) propels the experience of an improvised solo as unintentional. This experience of responding is compounded by collaborative improvisation - jazz often is not a solo

endeavour. Because even those accompanying the soloist are improvising, new directions are constantly suggested and responded to. There is seldom a risk of improvisers needing to search for something to play - both what they themselves have already played, and the playing of others present ample material to respond to. Thus, jazz musicians need only keep themselves open to what is going on in the moment to create something new.

\section{How Do Jazz Musicians Modulate Intentional Control When Improvising?}

We conceptualize intentional and unintentional not as two dichotomous states that musicians switch between, but rather as co-existing aspects of improvisation. Jazz musicians modulate intentional control using three main practices described below: (a) letting go, (b) using a "third ear" and (c) grabbing hold. As illustrated above, jazz musicians are aware that they benefit from relinquishing conscious control of their actions, but often find it difficult to do so. Psychological research has shown that trying to "control" what our mind does not do often has ironic results. For instance, trying not to think of something results in thinking more about it (e.g., Wegner, 1994). If being “in control” is one's default mode of operation, the problem of intentionally disengaging intentional control (i.e., letting go) is much more difficult than re-engaging intentional control (i.e., grabbing hold). Thus, although the paradox of intention in jazz theoretically involves both disengaging and (re)engaging intentional control, the problem of disengagement is seen as the more difficult of the two and thus has received more attention from jazz musicians.

Letting go: Disengaging intentional control. Jazz musicians engage in several practices that enable them to intentionally influence when they engage and disengage 
intentional control of their actions. The first step in intentionally controlling intention is therefore to be aware that intentional control creeps in unnoticed - the "inner monologue" of what one should do often arises whether it is wanted or not. Common catalysts of intentional control are self-criticism and self-doubt. There is always an "inner critic" evaluating and judging the quality of one's own performances. Such critical reflection is a necessary part of practice and aids musicians in acquiring the skills necessary to improvise. However, it brings with it a desire to correct unwanted aspects of a performance. Giving in to this impulse to rectify perceived problems takes one out of listening and into trying to control the performance.

Because one cannot stop and fix music during an improvisation, jazz musicians must learn to ignore this inner critic during performance - to "let go" of the impulse to exercise intentional agency. As trumpeter Miles Davis famously noted, that there are "no mistakes" in jazz improvisation. To manage this inner voice, musicians turn to practices that are similar to meditation and mindfulness (Nachmanovitch, 1990). For instance, in his well-known selfhelp book Effortless Mastery: Liberating the Master Musician Within, pianist Kenny Werner included a series of meditations and self-affirmations for jazz musicians. Such exercises tend to emphasize a radical focus on the present. Such practices and beliefs are thought to help musicians control when they relinquish deliberate control of their playing.

\section{Using a "third ear": Creating a passive observer role for conscious intention.}

Creative workers often forge strong links between their self-concept and what they create (e.g., Elsbach \& Flynn, 2013; Rouse, 2016; Baer \& Brown, 2012). Jazz musicians are no different - they view their playing as reflections of themselves (Goncalo \& Katz, 2019). However, this linkage between self and music inhibits improvisers' ability to let go. Like Bob Brookmeyer's advice to the first author to "stop listening like your ears are on your head," expert jazz musicians often imagine that their sense of deliberate, conscious control is 
physically separate from the active, improvising self. As Fred Hersch put it, “it's like you've got this third ear that oversees the whole business — the craft part — and that's what tells you what to do when you solo" (Berliner, 1994, p. 207). This "third ear" approach allows jazz musicians to temporarily weaken the link between their identities and what they are doing in the moment. This separation between conscious control and the improvising self does not mean that intention is gone - it is still simultaneously present with intuitive action. However, jazz musicians work toward being able to keep the impulse toward control off to the side, as a listener, rather than as the primary driver of action.

Grabbing hold: Re-engaging intentional control. The same "third ear" approach is also necessary to grab hold of intentional agency again after one has let go. However, little effort is necessary to re-engage intentional control - a momentary shift in attention away from the flow of action toward a thought or emotion is enough. Moments of grabbing hold can highlight attractive ideas that seem worthy of further pursuit, such as an interesting phrase or interplay between instruments. Re-engaging intentional control is also useful when coordination is failing - when someone has failed to uphold the "minimal structures" of the piece, when the band is out of synch, or when one's attention has simply wandered too far away (the first author remembers many times on stage where he missed cues to begin playing). In such instances, momentarily listening to others and shifting attention to the harmonic or rhythmic structure is sufficient to identify where one's bandmates are. A look or subtle nod is enough for most musicians to re-engage control and re-coordinate.

In other words, attending to and highlighting an aspect of the musical structure is all the work that intention needs to do. By internalizing and trusting harmonic and rhythmic structures (e.g., memorizing and "hearing" the repeating harmonic rhythm that melodic improvisations take place in reference to, role structures (e.g., piano/guitar are primarily responsible for keeping the harmonic structure, drums are primarily responsible for keeping 
the rhythmic structure, bass does both), and social norms (order of instruments soloing, rough equivalence of solo lengths), musicians can reduce conscious control over their actions without fearing for utter collapse of the music.

\section{Discussion}

We explored the paradox of intentionality in improvisation by focusing on the experiences and practices of jazz musicians. Our analysis suggests that this paradox cannot be resolved through careful planning or mindless action, but rather is managed in real time by modulating intentional control. To modulate their own operation of control, jazz musicians decouple their sense of self (letting go) while placing it as a passive observer (using a third ear) that is ready to re-engage intentional control (grabbing hold) when needed, after which the cycle can repeat as necessary.

We propose three main contributions of our analysis. The first contribution we offer is that we highlight how paradox is embedded within improvisational processes in organizations - especially when creativity is desired. Letting go allows familiar patterns of thought based on planning and habit to recede into the background so that people can see the flow of action and their environment without being overly committed to the current course of action. The third ear passively monitors the situation for interesting and novel ideas to build on, while simultaneously keeping conscious intention ready in case of coordination challenges. Conscious intention can thus quickly grab hold of these opportunities and challenges, offering subtle, loose guidance to the flow of ideas. Like jazz improvisation, creative problems cannot be fully defined in advance (Dillon, 1982; Unsworth, 2001) - they are explored and defined through action (Joas, 1996; Hua \& Fisher, 2020). Indeed, the creative process always involves momentary, spontaneous steps into the novel and unknown (Ford, 1996; Long Lingo \& O’Mahony, 2010); in other words, it has an inherent aspect of improvisation (Fisher \& Amabile, 2009; Hua \& Fisher, 2020). Thus, analytical, deliberate 
approaches are often at odds with the creative process's most uncertain and ambiguous aspects. Modulating intentional control makes room for intuition (Dane \& Pratt, 2007), emotion (Schwarz \& Clore, 2003), and serendipity, enabling creative responses to others (Hargadon \& Bechky, 2006; Smets, Morris, \& Greenwood, 2012) and the situation (Hutchins, 1991; Weick, 1993), thus serving as a micro-process that enables people to manage a paradox between the familiar and the novel (Ford, 1996; Weick, 1998). Future research might investigate the links between the ability to modulate intentional control and paradoxical mindsets (i.e., "the extent to which one is accepting of and energized by tensions" (Miron-Spektor et al., 2018, p. 26), which has been shown to engender creativity.

Our second contribution is to highlight practices endemic to an asymmetrical paradox. The practices detailed above combine to manage the shifting interplay between cognition and action as improvisation unfolds. In letting go, jazz musicians emphasize a duality between thinking and doing. However, experiencing this duality is the exception, not the ruleintentional control is typically experienced as an integral part of the self. The practice of letting go thus creates tension, like stretching a rubber band out of its original shape; grabbing hold allows the rubber band to snap back to its familiar shape. The paradox is thus asymmetric - not two equal, opposing forces, but a tension that is intentionally created to facilitate creative improvisation, but reintegrated when the action sequence is over. Like jazz improvisers, organizational actors have routines and roles that may feel "normal" to them. What is effortful and intentional is perceiving the two poles separately in the first place. When that effort is removed, the paradox seems to disappear. Such an asymmetrical approach adds to prior theory on managing organizational paradoxes, in which there is usually a balance of attention to managing the two poles (Schad, Lewis, Raisch, \& Smith, 2016; Beech, Burns, Caestecker, MacIntosh, \& MacLean, 2004). 
Third, examining the tension between control and letting go that jazz improvisers face reveals the complexity of the experience of paradox. Although improvisation has been conceptualized as a way of managing the paradox of planning and action (Clegg et al., 2002), the process of improvisation itself contains paradoxes. It appears that investigating a paradox from a practice perspective and focusing on "the every day doings and sayings unfolding in the moment" (Le \& Bednarek, 2017, p. 492) reveal alternative ways of managing tensions. As Beech and colleagues (2004) pointed out, paradox "cannot always be resolved through cognitive processes" and is instead kept open by "serious playfulness," which is inexorably linked to improvisation and creativity. More broadly, focusing on practices and experience in organizational paradox (Le \& Bednarek, 2017; Jarzabkowski and Le, 2017; Jarzabkowski, Bednarek, \& Le, 2018), improvisation (Cunha et al., 2017; Fisher \& Barrett, 2019; Hadida et al., 2015), and creativity (Harvey, 2014; Harrison \& Rouse, 2014) underscores the need for further integration among organizational research on improvisation, creativity, and paradox.

\section{Practical Implications}

Putting these practices in action, however, is not easy in jazz or in organizations and structures need to be put in place to facilitate them. Similar to jazz musicians who intentionally put their rational control on hold, people need physical or mental spaces where organizational or professional rules and expectations are suspended to enable exploration and creativity (Demir-Caliskan \& Fisher, 2020). Indeed, organizations often create physical spaces dedicated to creativity and experimentation, such as innovation labs (Lewis \& Moultrie, 2005) and "experimental spaces" (Cartel, Boxenbaum, \& Aggeri, 2019; Bucher \& Langley, 2016), which seek to free employees of some of the intentional control devices of formal roles and procedures. The logic of these spaces is that informality and serendipity will evoke learning and creativity (Furnari, 2014). Such efforts are only likely to succeed, however, when people suspend their usual perspectives and ways of thinking (Cronin \& 
Loewenstein, 2018) - and trying not to try is likely to be quite valuable in doing so. Therefore, organizations seeking to inspire creativity and learning through structural interventions may further need to provide guidance on how to modulate intentional control.

To apply lessons about modulating intentional control in groups and organizations, the specific strategies of letting go and using a third ear may also be distributed between individuals, rather than being managed within an individual as jazz musicians describe. In other words, people can rely on others to serve as a "third ear." For instance, in teaching hospitals, experienced physicians delegate active agency to less experienced ones, but continue to oversee the process and step in as necessary (Klein, Ziegert, Knight, \& Xiao, 2006). Those in "active control" roles can still focus on real time response, but rely on others to provide feedback and help to the larger system (see also Bechky \& Okhuysen, 2011; Hutchins, 1991; Weick \& Roberts, 1993). The result is that those letting go can feel more comfortable relinquishing control and even experimenting with their responses because they have faith that those in the third ear role are there to serve as a safety net and to identify new ideas. As long as these roles are understood to be complementary and not conflicting, the paradox of intentionality may actually be easier to navigate by using others.

\section{Conclusion}

In this chapter, we have adopted a novel perspective on improvisation within organizational studies to focus specifically on the paradox of intention. In doing so, we have attempted to advance the continuing conversation on how organizational life involves inherent tensions between control and freedom, in which creativity can thrive in the liminal space between the planned and the emergent. The management of creativity and paradox all involve not only accepting tensions involved, but real-time modulation between the two poles that is difficult to achieve with ordinary patterns of thought and action. And, despite the difficulty of controlling our own thoughts, those whose work takes place within a tension find 
Running Header: INTENTION AND JAZZ IMPROVISATION

ways to affect their subjective experience in ways that seem logically at odds. And, while trying to manage paradoxes creatively is necessary, it may be just as valuable to explore how, when, and why members of organizations might seek to address tensions by trying not to try. 


\section{References}

Adler, P. S., Goldoftas, B., \& Levine, D. I. (1999). Flexibility versus efficiency? A case study of model changeovers in the Toyota production system. Organization Science, 10(1), 43-68.

Baer, M., \& Brown, G. (2012). Blind in one eye: How psychological ownership of ideas affects the types of suggestions people adopt. Organizational Behavior and Human Decision Processes, 118(1), 60-71.

Balliett, W. (1959). The sound of surprise: 46 pieces on jazz. New York: Dutton.

Bechky, B. A., \& Okhuysen, G. A. (2011). Expecting the unexpected? How SWAT officers and film crews handle surprises. Academy of Management Journal, 54(2), 239-261.

Beech, N., Burns, H., de Caestecker, L., MacIntosh, R., \& MacLean, D. (2004). Paradox as invitation to act in problematic change situations. Human Relations, 57(10), 1313-1332.

Berliner, P. (1994). Thinking in jazz: The infinite art of improvisation. Chicago: University of Chicago Press.

Bucher, S., \& Langley, A. (2016). The interplay of reflective and experimental spaces in interrupting and reorienting routine dynamics. Organization Science, 27(3), 594-613.

Cartel, M., Boxenbaum, E., \& Aggeri, F. (2019). Just for fun! How experimental spaces stimulate innovation in institutionalized fields. Organization Studies, 40(1), 65-92.

Chia, R. (1996). The problem of reflexivity in organizational research: Towards a postmodern science of organization. Organization, 3(1), 31-59.

Chung, C. C., \& Beamish, P. W. (2010). The trap of continual ownership change in international equity joint ventures. Organization Science, 21(5), 995-1015.

Clegg, S. R., Cunha, J. V., \& Cunha, M. P. (2002). Management paradoxes: A relational view. Human Relations, 55(5), 483-503.

Cronin, M. A., \& Loewenstein, J. (2018). The craft of creativity. Stanford, CA: Stanford University Press.

Cunha, M. P., Miner, A. S., \& Antonacopoulou, E. (2017). Improvisation processes in organizations. In A. Langley \& H. Tsoukas (Eds.), Sage handbook of process organization studies (pp. 559-573). Los Angeles: Sage.

Dane, E., \& Pratt, M. G. (2007). Exploring intuition and its role in managerial decision making. Academy of Management Review, 32(1), 33-54.

Demir Caliskan, O. \& Fisher, C. M. (2020, August). Project switches in collective creative spaces: An inductive study of makerspaces. In O. Demir Caliskan \& M. Hua (Chairs), New Perspectives on Developmental Sequences and Cycles in Creative Work. Symposium presented at the meeting of the Academy of Management, Vancouver, B.C

Dillon, J. T. (1982). Problem finding and solving. The Journal of Creative Behavior, 16(2), 97111.

Eisenberg, E. M. (1990). Jamming: Transcendence through organizing. Communication Research, $17(2), 139-164$.

Elsbach, K. D., \& Flynn, F. J. (2013). Creative collaboration and the self-concept: A study of toy designers. Journal of Management Studies, 50(4), 515-544. 
Fisher, C. M., \& Amabile, T. M. (2009). Creativity, improvisation and organizations. In T.

Rickards, M. A. Runco, \& S. Moger (Eds.), The Routledge companion to creativity (pp. 1324). New York: Routledge.

Fisher, C. M., Ananth, P., \& Demir-Caliskan, O. (2020). A winding road: Teresa Amabile and creative process research. In R. Reiter-Palmon, C. M. Fisher, \& J. Mueller (Eds). Creativity at work: A festschrift in honor of Teresa Amabile. London, UK: Palgrave Macmillan.

Fisher, C. M., \& Barrett, F. J. (2019). The experience of improvising in organizations: A creative process perspective. Academy of Management Perspectives, 33(2), 148-162.

Ford, C. M. (1996). A theory of individual creative action in multiple social domains. Academy of Management Review, 21(4), 1112-1142.

Furnari, S. (2014). Interstitial spaces: Microinteraction settings and the genesis of new practices between institutional fields. Academy of Management Review, 39(4), 439-462.

Goncalo, J. A., \& Katz, J. H. (2019). Your soul spills out: The creative act feels self-disclosing. Personality and Social Psychology Bulletin, 1-14.

Hadida, A. L., Tarvainen, W., \& Rose, J. (2015). Organizational improvisation: A consolidating review and framework. International Journal of Management Reviews, 17(4), 437-459.

Hargadon, A. B., \& Bechky, B. A. (2006). When collections of creatives become creative collectives: A field study of problem solving at work. Organization Science, 17(4), 484-500.

Harrison, S. H., \& Rouse, E. D. (2014). Let's Dance! Elastic Coordination in Creative Group Work: A Qualitative Study of Modern Dancers. Academy of Management Journal, 57(5), 1256-1283.

Harvey, S. (2014). Creative synthesis: Exploring the process of extraordinary group creativity. Academy of Management Review, 39(3), 324-343.

Hua, M. \& Fisher, C. M. (2020, August). Re-defining problems and developing ideas through elaborative play: An inductive study of circus R\&D. In S. Harrison, A. Carlsen, \& M. Skerlavaj (Chairs), Broadening our insight: Bridging and blurring boundaries between creativity and innovation. Symposium presented at the meeting of the Academy of Management, Vancouver, B.C.

Hutchins, E. (1991). Organizing work by adaptation. Organization Science, 2(1), 14-39.

Ingram, A. E., Lewis, M. W., Barton, S., \& Gartner, W. B. (2016). Paradoxes and innovation in family firms: The role of paradoxical thinking. Entrepreneurship Theory and Practice, 40(1), 161-176.

Jarzabkowski, P., Bednarek, R. \& Lê, J. (2018). Studying paradox as process and practice: Identifying and following moments of salience and latency. In W. Smith, M. Farjoun, A. Langley and H. Tsoukas (Eds.), Perspectives on process studies. Oxford University Press: Oxford.

Jarzabkowski, P. A., \& Lê, J. K. (2017). We have to do this and that? You must be joking: Constructing and responding to paradox through humor. Organization Studies, 38(3-4), 433462.

Joas, H. (1996). The creativity of action. University of Chicago Press. 
Klein, K. J., Ziegert, J. C., Knight, A. P., \& Xiao, Y. (2006). Dynamic delegation: Shared, hierarchical, and deindividualized leadership in extreme action teams. Administrative Science Quarterly, 51(4), 590-621.

Le, J. \& Bednarek, R. (2017). Paradox in everyday practice. In P. Jarzabkowski, A. Langely, M. Lewis, \& W. Smith (Eds.), Oxford handbook of organizational paradox: Approaches to plurality, tensions, and contradictions. Oxford University Press: Oxford.

Lewis, M., \& Moultrie, J. (2005). The organizational innovation laboratory. Creativity and Innovation Management, 14(1), 73-83.

Lewis, M. W. (2000). Exploring paradox: Toward a more comprehensive guide. Academy of Management Review, 25(4), 760-776.

Lingo, E. L., \& O'Mahony, S. (2010). Nexus work: Brokerage on creative projects. Administrative Science Quarterly, 55(1), 47-81.

Miron-Spektor, E., Ingram, A., Keller, J., Smith, W. K., \& Lewis, M. W. (2018).

Microfoundations of organizational paradox: The problem is how we think about the problem. Academy of Management Journal, 61(1), 26-45.

Nachmanovitch, S. (1990). Free play: Improvisation in life and art. New York: Penguin Putnam.

Orlikowski, W. J. (1996). Improvising organizational transformation over time: A situated change perspective. Information Systems Research, 7(1), 63-92.

Peplowski, K. (1998). The process of improvisation. Organization Science, 9(5), 560-561.

Poole, M. S., \& Van de Ven, A. H. (1989). Using paradox to build management and organization theories. Academy of Management Review, 14(4), 562-578.

Rouse, E. D. (2016). Beginning's end: How founders psychologically disengage from their organizations. Academy of Management Journal, 59(5), 1605-1629.

Schad, J., Lewis, M. W., Raisch, S., \& Smith, W. K. (2016). Paradox research in management science: Looking back to move forward. Academy of Management Annals, 10(1), 5-64.

Schwarz, N., \& Clore, G. L. (2003). Mood as information: 20 years later. Psychological Inquiry, 14(3-4), 296-303.

Smets, M., Morris, T., \& Greenwood, R. (2012). From practice to field: A multilevel model of practice-driven institutional change. Academy of Management Journal, 55(4), 877-904.

Smith, E. R., \& DeCoster, J. (2000). Dual-process models in social and cognitive psychology: Conceptual integration and links to underlying memory systems. Personality and Social Psychology Review, 4(2), 108-131.

Unsworth, K. (2001). Unpacking creativity. Academy of Management Review, 26(2), 289-297.

Waldman, D. A., Putnam, L. L., Miron-Spektor, E., \& Siegel, D. (2019). The role of paradox theory in decision making and management research. Organizational Behavior and Human Decision Processes, 155, 1-6.

Wegner, D. M. (1994). Ironic processes of mental control. Psychological Review, 101(1), 34.

Weick, K. E. (1993). The collapse of sensemaking in organizations: The Mann Gulch disaster. Administrative Science Quarterly, 38(4) 628-652. 
Weick, K. E. (1998). Introductory essay: Improvisation as a mindset for organizational analysis. Organization Science, 9(5), 543-555.

Weick, K. E., \& Roberts, K. H. (1993). Collective mind in organizations: Heedful interrelating on flight decks. Administrative Science Quarterly, 357-381.

Werner, K. (1996). Effortless mastery. New Albany, IN: Jamey Aebersold Jazz. 